\title{
O All-news com sotaque brasileiro
}

\author{
Cândida Emília Borges Lemos ${ }^{1}$ \\ Ana Carolina Vitorino de Melo Costa ${ }^{2}$
}

Resumo: Este artigo trata da investigação sobre o processo de produção e de recepção do formato por ouvintes de rádio all-News, com estudo de caso da BandNews FM de Belo Horizonte, capital do estado de Minas Gerais, Brasil. Apresenta a discussão sobre este formato de rádio na bibliografia especializada, com análise de conteúdos e contextualização do formato no Brasil. Aborda também o all-news no contexto da interatividade entre produtores e ouvintes/internautas em ambientes virtuais.

Palavras-chave: radiojornalismo, formatos radiofônicos; all-News; BandNews.

Abstract: This work is about the production, the methodology and logistics of the radio station Band News FM 89,5 , which is broadcasted in the city of Belo Horizonte, capital of Minas Gerais, Brazil, which has the all news format, reporting only news. It presents a discussion on this radio format in professional literature with content analysis and contextualization of the format in Brazil. Also addresses the all-news in the context of interaction between producers and listeners / internet users in virtual environments.

Key-words: radiojournalism, radio formats, all-news, BandNews.

\section{Introdução}

Este trabalho versa sobre a rádio Band News FM 8,9, que é transmitida na cidade de Belo Horizonte, capital do estado de Minas Gerais, Brasil, que tem o formato all-news, com a veiculação apenas de notícias. A emissora, desde 2005, perfila-se neste formato e traz de 20 em 20 minutos boletins nacionais com os principais destaques do momento. Seu slogan é “Em 20 minutos, tudo pode mudar". Ela opera em rede nacional, na qual as notícias variam de locais para nacionais. O importante, é que haja circulação de informações durante toda a programação.

O formato all-news é extremamente importante porque sempre vai disponibilizar aos interessados as notícias mais importantes do dia, além de trazer análises e programas

${ }^{1}$ Doutora em História (Universidade do Porto, Portugal), Mestre em Ciência Política (UFMG), Graduada em Comunicação Social, hab. Jornalismo (PUC Minas); professora-adjunta dos cursos de Jornalismo e Publicidade (Centro Universitário UNA). Coordenadora do Centro de Investigação da Mídia da UNA, desde 2012. Integra o Grupo de Pesquisa Produção Criativa em Comunicação do Instituto de Comunicação e Artes da UNA cadastrado no CNPq (2014). candida.lemos@prof.una.br.

${ }^{2}$ Graduada em Jornalismo Multimídia pela UNA. Foi trainee em 2014/2015 na Band News FM em Belo Horizonte. Email: anacarol.vmc@hotmail.com 
interativos, que despertam o interesse do público. Nesse caso, as entrevistas e conversas integradas às notícias fazem do all-news, all-news and talk. Forma de transmitir informação também muito interessante, por não ser tão dura quanto um impresso nem tão superficial como em alguns casos de web. A própria internet beneficiou-se com esse formato radiofônico. Quem deseja ouvir músicas, por exemplo, procura diretamente em um site do segmento o tipo ou artista que achar melhor, no momento que for preciso.

Nesta perspectiva, esta pesquisa busca responder como a Band News busca cativar seus ouvintes? Quais estratégicas são utilizadas para a organização da redação e equipe de reportagem? Há interatividade entre a equipe de produção da emissora e os ouvintes por meio de rede sociais da web? A Band é ó principal meio informativo pelo qual os ouvintes se informam? Qual a confiabilidade o ouvinte afere à emissora? Para responder a essas perguntas foram realizadas entrevistas com os produtores da emissora e também com ouvintes.

Entre os assuntos tratados, estarão o ritmo de produção, a metodologia e logística da rádio, a interatividade e a percepção do ouvinte ao estar sintonização em uma emissora allnews.

Ao se considerar o papel e as características do rádio e a partir da pesquisa sobre o tema, delimitou-se o estudo sobre o formato all-News. Dentre os vários tipos de rádio, este formato se destaca pelas polêmicas positivas e negativas. Nesta pesquisa foram realizadas entrevistas de profissionais que trabalham na área, para se conhecer em mais detalhes o cotidiano da emissora Bem como, foram realizadas entrevistas com ouvintes da emissora para entender melhor o que os fideliza a um rádio direcionada à veiculação de notícias em sua essência.

\section{$O$ construir de uma media pessoal}

O primeiro jornal de rádio do Brasil foi criado por Roquette-Pinto, na Rádio Sociedade do Rio de Janeiro. Era o Jornal da Manhã. Milton Jung conta como era produzido o primeiro programa jornalístico do país:

Com um lápis vermelho na mão, o professor Edgar Roquette-Pinto lia atentamente os principais jornais do Rio de Janeiro. A notícias mais interessantes ou fatos curiosos eram sublinhados, tarefa encerrada só depois de virada a última página. Os textos rabiscados eram a fonte de informação para o Jornal da Manhã, uma das primeiras experiências jornalísticas do rádio brasileiro, transmitindo, de segunda a 
sexta, pela Rádio Sociedade do Rio de Janeiro, a PRA-02. O programa não tinha hora certa para começar. Ou melhor, tinha: assim que Roquette-Pinto terminasse a leitura dos jornais impressos. Era o tempo de telefonar para o estúdio da emissora e pedir para o técnico colocar a rádio no ar. O próprio Roquette Pinto lia as notícias. Mal imaginava que seu método contaminaria as redações. (JUNG, 2011, p. 19)

Na capital de Minas Gerais, Belo Horizonte, o rádio chegara em 1927, quando foi criada a Rádio Mineira, que era basicamente uma rádio pública, que veiculava ações do governo estadual, informações sobre a bolsa e aplicações do café e do algodão. (Prado, 2012)

Nos anos seguintes, foi criada a rádios Inconfidência, que continua se destacar na cidade. Além disso, em 1951, nasce um ícone do rádio nacional e a líder de audiência na região metropolitana: a rádio Itatiaia (Carneiro, 2002). Quando criada, a rádio Itatiaia cobriu importantes acontecimentos na capital e era única que mantinha a programação durante as 24 horas do dia. Carneiro queria montar queria implementar em Belo Horizonte um modelo diferente do que já existia, uma rádio mais informativa com enfoque no esporte.

Irmão do meio na família do jornalismo, o rádio está entre o impresso - primogênito -, a TV, e a internet - o "caçula". Reúne aspectos das mídias concorrentes e apresenta diferenciais que o mantêm no mercado, até os dias atuais. Por ser considerado o mais popular dos meios de comunicação, talvez o rádio ofereça um lugar especial no jornalismo, que precisa informar a todos, de alguma forma. E o jeito do rádio algumas vezes é mais simples.

O preço do aparelho e a gratuidade na recepção de sinal facilitam a vida desse media, como comenta André Barbosa Filho (2003):

Livre de fios e tomadas, o rádio pode ser levado a qualquer lugar. Isso faz dele uma mídia pessoal e que pode ser 'ouvida' onde o receptor desejar. Em quase todas as circunstancias, sem grandes problemas: no carro, na rua, na cozinha, no campo de futebol, no curral da fazenda ou no bar da esquina, de infinitos modos. A pessoas simplesmente ouvem, realizando outras tarefas, sem se incomodar. (BARBOSA FILHO, 2003, p. 48).

Talvez a principal vantagem do rádio seja a própria facilidade para seus receptores, já que podem fazer diversas atividades ao som de sua estação preferida. O que ocorre, muitas vezes, é um apego àquele programa que se ouve todo dia. A intimidade que é criada quando uma família, por exemplo, tem o costume de ouvir todos os dias o mesmo âncora, no mesmo horário. Por isso, os apresentadores de rádio utilizam bordões piegas para "reforçar os laços" 
com o ouvinte, como lembra Magaly Prado (20012). Esta particularidade deste meio comunicativo, o se se falar ao pé do ouvido de seu público, como se locutor se comunicasse diretamente a cada um particularmente de sua audiência permanece atual e se constitui em característica singular do rádio existência:

O tom íntimo das transmissões, representado pelas expressões 'amigo ouvinte', 'caro ouvinte', 'querido ouvinte', proporciona uma aproximação e uma intimidade únicas, fazendo do rádio um veículo companheiro. Antes, a audiência era coletiva. $\mathrm{E}$ em áreas rurais pouco beneficiadas com a tecnologia, ainda se registra a recepção radiofônica grupal: as pessoas dos vilarejos se reúnem para ouvir as notícias transmitidas de um rádio apenas. (BARBOSA FILHO, 2003, p. 47).

A prestação de serviços e o cunho social acompanham a história do rádio (Barbosa Filho, 2003; Barbeiro \& Oliveira,2003). Esta media pode ser utilizado como ferramenta em uma comunidade e prestar serviços a uma determinada parcela da população. Neste contexto, "exerce uma comunicação que em muito contribui para a história da humanidade. Deixa como legado princípios como ação, atuação, transformação e mobilização. (Barbosa Filho, 2003.)

Sobre o processo de segmentação em rádio, o estudioso de rádio Luiz Artur Ferraretto acredita que

\footnotetext{
O processo de concentração de uma rádio em um dado segmento pode englobar apenas alguns programas ou a totalidade das transmissões (...). Significa oferecer um serviço com destinatário definido, buscando também anunciantes adequados a esses ouvintes específicos. Alguns critérios vão referenciar o corte feito na audiência total para ir ao encontro de um público-alvo. $(2015,48)$.
}

Um dos grandes desafios do meio rádio na contemporaneidade diz respeito a como o veículo se coloca frente às tecnologias e aos dispositivos que permitem a interatividade de mídias e abre novos possibilidades à comunicação sonora. Sobre o impacto da internet e da digitalização de áudios, Álvaro Bufarah Junior diz que “após a onda sonora ser convertida em um conjunto de códigos binários, os arquivos podem ser combinados facilitando a edição, transporte e veiculação" (2010, p. 169). A digitalização do áudio possibilita que os conteúdos estejam disponíveis em "suportes diferentes, facilitando o acesso e portabilidade dos arquivos e até a transmissão ao vivo de eventos" (Bufarah, p. 170).

O estudioso espanhol Balsebre (2013) questiona se rádio pode chegar a se converter em uma nova mídia sonora, no contexto da nova sonosfera, para os novos ouvintes-Questiona 
também se pode o rádio constituir-se na principal referência das novas mídias sonoras, independentemente dos aparatos tecnológicos de reprodução que possam ser utilizados.

Balsebre responde que sim. Mas estabelece algumas condições: como o “posicionamento que, espero eu, terá o rádio na nova sonosfera, na qual os meios tradicionais irão conviver com os novos meios". Para ele, o rádio só conseguirá sobreviver nestes novos tempos se não continuar subestimando a importância de ter uma boa história, "de ter vozes de grande qualidade, boas histórias sonoras, bem narradas Se não continuar subestimando a importância de ter um bom departamento especializado em criatividade sonora." (Balsebre, 2013, p. 22).

\section{Testemunha da história na construção noticiosa}

Um longo caminho havia de ser percorrido entre o início do rádiojornalismo e as atuais all-news. As notícias eram cópias literais das que eram publicadas em jornais impressos e também não havia as reportagens externas, portanto, todo o conteúdo era produzido de dentro do estúdio, sem reportagens externas que tanto trazem dinamicidade ao radiojornalismo. (Betti \& Meditsch, 2008)

Às 12 h55 do dia 28 de agosto de 1941, estreia o Repórter Esso, na Rádio Nacional do Rio de Janeiro. O programa consagrou na voz de Heron Domingues: "Prezados ouvintes, bom dia. Aqui fala o Repórter Esso, testemunha ocular da história, apresentando as últimas notícias da UPI." Com o Repórter Esso, Nascia no país uma linguagem específica para o radiojornalismo. (Jung, 2004).

Já a primeira rádio all-news foi implementada em 1961, no México, mais especificamente em Tijuana. A emissora Xetra, que era especializada em músicas de rock and roll, resolveu experimentar um novo formato, devido a quantidade de notícias que chegava à redação diariamente. Eles passaram a veicular apenas notícias e assim nascia o all-news. (Paula, 2006).

Apesar da pioneira nesse modelo ter sido mexicana, foi nos Estados Unidos que o allnews ganhou destaque, com a rádios WCBS e WINS, que mantinham inúmeros repórteres nas ruas com entradas ao vivo em suas programações. (Betti \& Meditsch 2008) 
Desses exemplos, saiu a inspiração para o formato no Brasil. A primeira tentativa ocorreu na década de 1980, com a rádio Jornal do Brasil AM. Eles reformularam a grade de programação e substituíram todo o conteúdo por notícias. Não deu certo, seis anos depois a rádio voltou a transmitir músicas em sua programação diária. (Betti \& Meditsch, 2008)

A estudiosa do rádio brasileiro Virgínia Moreira (1987) apresenta uma entrevista com o então chefe do Departamento de Jornalismo da rádio Jornal do Brasil Carlos Augusto Drummond, na qual ele atribui o fracasso do experimento all-news à falta de recursos para a contratação de pessoal e de investimento técnico. É inegável que o formato exige recursos da emissora, para a produção de conteúdos significativos e a realização de entrevistas.

Foi em 1991 que o formato estadunidense foi incorporado de vez ao radiojornalismo brasileiro.Com a junção da Rádio Excelsior, de São Paulo e a Eldorado, do Rio de Janeiro, era criada a Central Brasileira de Notícias, a CBN, do Sistema Globo de Rádio. (Jung, 2011.)

Foi a TV norte-americana, através da $C N N$, que inspirou a formação da $C B N$, pelas Organizações Globo (Jung, 2011). O publicitário Nizan Guanaes criou o slogan da emissora: “A rádio que toca notícias". E a metodologia era a seguinte: São Paulo e Rio interagiam durante a programação. Mais tarde, a rede seria ampliada para Belo Horizonte e Brasília. Além de mais de 30 emissoras afiliadas.

$\mathrm{Na}$ esteira do formato, o all-news brasileiro foi brindado com a BandNews FM, que surgiu em 2005, pertencente ao Grupo Bandeirantes, um dos conglomerados de media mais poderosos do país, que reúne mais de 40 empresas integradas nas mais diversificadas plataformas de comunicação. Hoje, a rádio traz de 20 em 20 minutos boletins nacionais com os principais destaques do momento. Seu slogan é “Em 20 minutos, tudo pode mudar".

O formato das rádios all-news é basicamente constituído por notícias que que são veiculadas durante as 24 horas do dia. Nos casos das redes, as notícias variam de locais para nacionais. O importante, é que haja circulação de informações durante toda a programação. Betti e Meditsch (2008) alertam ao fato de esta forma de produção ser arriscada, devido à repetição de conteúdo durante o dia: "Não resta dúvida que tal caducidade, embora admitida pela expectativa de uma audição por tempo limitado, não é desejável, e que no acirramento da concorrência levará a melhor em frequência de audição uma emissora que consiga reduzi-la em relação às demais" (p. 7). Porém, há que se levar em conta as questões orçamentárias, pois 
como já dito, a produção de notícias envolve custos financeiros. "Para o perfeito funcionamento do fluxo é a abundância de produção, e a possibilidade desta abundância é limitada por razões econômicas", aferem Betti e Meditsch (2008, p. 7).

Contudo, há outro fator que prejudica as emissoras que optam apenas pelo jornalismo: a competitividade. Como de costume neste ramo, uma empresa disputa com a outra quem é que vai noticiar determinado fato primeiro. É o que Jung (2011) tenta explicar:

\begin{abstract}
Durante muitos anos, o rádio abriu mão da exatidão da notícia, entendendo que sua qualidade estava em levar a informação o mais rápido possível ao ouvinte. O preço cobrado por essa opção foi alto. Perdeu credibilidade. Demorou a entender que a tarefa principal de seus profissionais era equacionar o problema: noticiar com precisão e agilidade. ( p.113)
\end{abstract}

A rapidez na informação também atrai o ouvinte e é um importante fator para o sucesso da rádio. A luta pelo "furo" sempre foi um alvo perseguido pelo jornalismo em geral e pela media rádio, em particular. Com o advento da internet, o "furo" de reportagem aguça esta disputa de quem irá noticiar um fato em primeira mão para as suas audiências. Porém, a qualidade da informação pode ser colocada em xeque. "Em veículos como o rádio e internet, a importância de se combinar agilidade com precisão é determinante para o sucesso". (Jung, 2011, p.111)

As rádios all-news têm buscado combinar a agilidade com a credibilidade. Além disso, elas procuram por uma peça "curinga", com a introdução de elementos diferenciados para a programação. Os comentários e programas de entrevistas adicionam novas ferramentas ao formato só notícias.

Ferraretto avalia que o formato das emissoras dedicadas 24 horas por dia à notícia, mesmo que assumam que sejam all-news ou apenas news, na prática "desenvolveram um formato intermediário mais próximo do talknews" (2013, p. 59). Neste contexto, a Gaúcha, do Grupo RBS, de Porto Alegre, capital do Rio Grande do Sul, Brasil, por exemplo, "aposta" no formato híbrido, com entrevistas, noticiário puro e reportagens. No caso da $C B N$, do conglomerado de media Organizações Globo, esta emissora se coloca como all-news, mas apresenta características do formato talk. Ferraretto acredita que a BandNews seja o projeto 
que mais se aproxima do all-news norte-americano, "que irradia blocos de 20 minutos com espaços padronizados com noticiário, prestação de serviços e comentários. Mesmo nela, há espaço para o talk, uma característica histórica do radiojornalismo brasileiro (2013, p. 60).

Por conta da produção para as emissoras all-news, o modelo de jornalismo proposto nesse tipo de rádio requer uma série de regras básicas, para manter a produção durante as 24 horas do dia. Em um manual que é entregue aos novos integrantes da equipe da rádio BandNews, elaborado pela antiga chefe de redação da Rádio, Flávia Ivo, alguns pontos cruciais para a apuração e a veiculação das notícias são impostos.

De acordo com o manual, tudo começa na fase da apuração, normalmente, realizada pelos estagiários, que contribuem para a alimentação de todos os veículos do grupo Bandeirantes Minas, são eles: Rádio BandNews FM, TV Band Minas, jornal Metro e TVO. (Grupo Bandeirantes de Comunicação [Band], 2005).

Nessa etapa, são feitas rondas telefônicas, com polícia, bombeiros, autarquias de transito e outras áreas, além de sites noticiosos e oficiais de governos e instituições para a produção de conteúdo. Também é importante estar atento aos demais canais de notícias, para identificar assuntos que ainda não estão sendo tratados na rádio.

Para a construção da nota, é preciso levar em conta alguns fatores que definem se um determinado assunto vale mesmo ser transformado em notícia. Conforme o manual, no que diz respeito à qualidade da notícia é importante observar os seguintes fatores: novidade, proximidade, tamanho e importância (Band, 2005, p.3)

Nos critérios de noticiabilidade, o documento orienta a equipe a fazer as seguintes indagações:

\footnotetext{
É interessante? Você já tinha ouvido falar sobre a notícia antes? Quantas pessoas serão afetadas? A matéria é de interesse para um número suficiente de pessoas? É um história difícil de contar? Se a história é difícil de contar provavelmente vale a pena ser contada. Tem certeza que o que lhe foi contado é verdadeiro? (Band, 2005, p.3)
}

Em consonância ao slogan "Em 20 minutos tudo pode mudar", o manual recomenda que a cada 20 minutos uma nova manchete deva ir ao ar com as informações mais importantes do momento. As chamadas escaladas abrem os jornais periódicos do dia e não podem ultrapassar 20 segundos de duração. Apesar de curtas, devem ser autossuficientes. Nos giros de repórteres durante o dia, ao final de cada entrada, o jornalista sempre informa a temperatura e condição do tempo na cidade. (Band, 2005) 
As manchetes com participação da Praça de Belo Horizonte são às 5h, 6h, 12h, 14h, $17 \mathrm{~h}$ e $18 \mathrm{~h}$. Os arquivos de áudio são disponibilizados para a rede por meio do programa File Transfer Protocol (FTP), pelo menos 20 minutos antes de a manchete ir ao ar. E cada praça deve mandar, no mínimo, três boletins diários com entrevistas, conhecidas como sonoras. (Band,2005)

Existem algumas normas para essas notas enviadas à rede nacional neste manual:

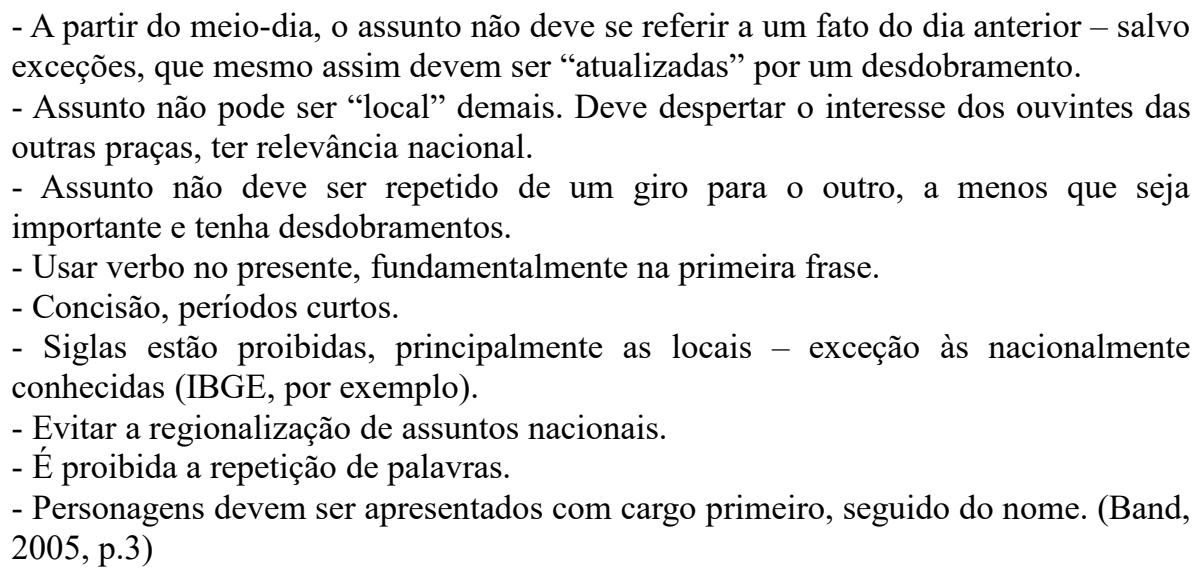

A duração de cada boletim também é previamente definida pelos finalizadores e podem ter, no máximo, um minuto e 40 segundos. A sonoras variam de 10 a 30 segundos. Em todas as assinaturas devem conter o local e nome do repórter e o slogan da rádio. (Band, 2005)

Com essa estrutura de trabalho, é montada a programação de conteúdos para uma emissora que transmite apenas notícias durante todo o dia. Além disso, alguns programas são veiculados, com entrevistas e discussões sobre determinados temas relevantes do dia. Diversas colunas sobre temas variados, como viagens, moda, filhos, esportes, cultura, entre outras, também compõem a grade de programação da emissora.

Em Belo Horizonte, dois jornais locais vão ao ar de segunda a sábado. O BandNews Minas $1^{\circ}$ edição, que era apresentado pelos jornalistas Lilavati Oliveira e Júnior Rezende e o $2^{\circ}$ edição, com Júlio Vieira, Júlio Prado e Juliana Lima, quando da realização desta pesquisa. 
Durante o dia, a ancoragem da rádio fica a cargo de quatro profissionais e as reportagens eram produzidas e realizadas por seis profissionais, entre os quais uma repórter específica para a área de esportes, Dimara Oliveira.

Já o manual de redação da rádio $C B N$, elaborado pela diretora de Jornalismo da emissora, Mariza Tavares, também define alguns itens básicos para a emissora, mas com alguns pontos diferentes do apresentado pela Band News. O slogan define a $C B N$ como "A rádio que toca notícia." Segundo Jung (2011), essa frase efeito traduz o espírito desse tipo de rádio: "O bordão 'a rádio que toca notícia' foi criado para a $C B N$ pelo publicitário Nizan Guanaes e prova que, com um pouco de esforço, imaginação e boa vontade, encontraremos uma expressão brasileira para substituir o all-news." (2011, p.44).

Com essa regra geral, a cada meia hora um giro nacional das notícias vai ao ar na $C B N$. O giro é composto por quatro ou seis assuntos diferentes, apresentados em ordem de importância decrescente. Essas notas não devem ultrapassar dois minutos de duração cada. A última nota sempre é sobre a bolsa de valores ou mercado financeiro. O manual ressalta que seria descabido a troca aleatória das notas apenas com a intenção de se criar a falsa impressão de mais diversidade de notícias. (Tavares, 2011)

O formato da CBN é semelhante ao da BandNews, com a produção em sinergia com a rede e com as regras básicas como a não repetição de palavras, a construção de frases curtas e diretas, apenas números mais importantes devem ser informados, entradas ao vivo com descrição de elementos que caracterizem a notícia, o não uso de palavrões e a estrutura das reportagens, com cabeça, sonora e pé.

A atividade em uma all-news começa bem cedo. O coordenador de rede, que está lotado em São Paulo, entra em contato com as várias praças distribuídas pelo Brasil. A praça de Belo Horizonte já envia, por volta das 9 da manhã, a pauta com os principais destaques que Belo Horizonte pode vender. "São assuntos interessantes, que compreendem Minas Gerais, lógico, mas que vale rede" conta a chefe de reportagem e âncora da rádio na época da produção do trabalho,_Lilavatti Oliveira. (L. Oliveira, comunicação pessoal, Maio, 6, 2015).

Nesta produção incessante de selecionar quais factos vão se transformar em notícia, o planejamento é ingrediente fundamental ao sucesso da programação diária. A produção 
sempre deve antecipar o máximo possível os temas a serem abordados no noticiário do dia seguinte, como explica Oliveira a rotina da redação:

A gente tem a pauta do dia e passa para distribuir para toda a equipe. Depois disso, eu no caso que monto a pauta pela manhã, separo os assuntos do dia, que vão ser trabalhados tanto no Jornal $2^{\circ}$ edição, quanto para os blocos e para a rede. E ai eu já coloco na pauta, já elenco na pauta, o que vai render pro dia seguinte. (L. Oliveira, comunicação pessoal, Maio, 6, 2015).

Segundo o ouvinte e bancário Lyon Antunes a principal razão dele escutar a Band News está na dinamicidade do fazer jornalismo: “Até mesmo os âncoras, os repórteres da rádio são pessoas mais jovens, que falam de uma maneira mais agradável até de se ouvir do que as outras rádios que têm um jeito muito mais sisudo". (L. Antunes, comunicação pessoal, Junho, 5, 2015).

Sobre os temas a serem abordados, o jornalista Júlio Vieira, que dividia o cargo de chefe de reportagem, repórter e âncora da rádio, na época da elaboração desta pesquisa, diz que os temas políticos estão entre os preferidos da emissora nos tempos atuais:

\begin{abstract}
Não só por ser um assunto muito importante, que sempre já teve relevância na rádio, mas por causa da situação atual do país. A gente dá um foco muito grande também na economia, trazendo destaque da bolsa de valores, destaque de índice de emprego, desemprego, inflação... enfim, aquilo que por mais que fale 'ah, economia, parece que tá tão distante da gente', mas não faz diferença total no dia-a-dia do cidadão. (J. Vieira, comunicação pessoal, Maio, 10, 2015).
\end{abstract}

A emissora, porém, busca quebrar a sisudez dos temas econômicos e políticos com a utilização de uma linguagem descontraída e, às vezes com um Back Ground (BG), para se conseguir leveza. Bárbara Vasconcellos avalia que a forma de noticiar com humor e em tom de conversa, que transmita a sensação de naturalidade facilita o entendimento do conteúdo pelo público: "Fica mais agradável com a nossa trilha que, modéstia à parte, é uma plástica muito bacana. E quando você coloca esse jeito conversado, esse jeito natural, nem parece que você tá dando notícia, que você tá falando uma coisa complicada de entender, muito pelo contrário". (B. Vasconcellos, comunicação pessoal, Junho, 2, 2015).

Outra estratégia da emissora para conseguir um ambiente descontraído é mesclar os temas mais áridos com notícias de entretenimento e cultura. Esta diversidade de temas, aliado à linguagem coloquial e o BG são os eixos que conferem perfil à emissora, na tentativa de 
fidelizar o ouvinte, mesmo se tratando de uma all-news. Oliveira diz que se objetiva deixar o ouvinte mais familiarizado com o assunto em pauta, de forma leve:

\begin{abstract}
A notícia passada com credibilidade, com riquezas de detalhes, mas sempre com um tom mais informal. Essa é a cara da BandNews, uma BandNews formada por profissionais muito jovens. Muito também com a pegada com o trabalho que é desempenhado do nosso principal âncora, que é o Ricardo Boechat. (L. Oliveira, comunicação pessoal, Maio, 6, 2015).
\end{abstract}

Nessa perspectiva, Vasconcellos conta que tenta conversar com o ouvinte como se ela estivesse dentro do carro dele, do lado dele, na casa ou no trabalho dele: "Me aproximar o máximo, usar a linguagem mais fácil que tem, e tentar não ser petulante nos meus comentários, porque é uma coisa muito perigosa, neh?”, indaga a então âncora da emissora (B. Vasconcellos, comunicação pessoal, Junho, 2, 2015).

Porém, há uma linha tênue que separa a notícia veiculada de forma mais leve e descontraída e da vulgaridade. Neste sentido, o estudioso da media rádio Álvaro Bufarah alerta que seja válido ser informal, mas não desrespeitoso: "é valido ser informal e não vulgar. Infelizmente nós temos várias situações dentro do país, onde as pessoas perderam o bom senso, a linha média entre o que é conteúdo, o que é conteúdo de qualidade, e o que é apelação". (A Bufarah, comunicação pessoal, Junho, 20, 2015).

Em relação ao onde se ouve a rádio, o hábito de ter uma emissora de rádio como fiel amiga enquanto enfrenta o tráfego pesado dos grandes centros urbanos se forma na opinião do ouvinte Lyon Antunes, pois ele conta que, na maioria das vezes, está com sintonizado na Band News quando "eu estou indo ou voltando do trabalho". Para ele, a emissora é o meio no qual "eu mais costumo buscar informação" (L. Antunes, comunicação pessoal, Junho, 5, 2015).

A portabilidade do rádio que antes ocorria por meio dos receptores de pilha, hoje, ganha nova versão. Os telefones móveis cumprem esta função, por acompanham as pessoas em seu cotidiano. O ouvinte Luiz Felipe Horta conta sua rotina e como o rádio nela se integra: "Eu vou de casa pro trabalho, vou almoçar a pé, volto pra casa a pé, vou fazer supermercado a pé, então nesse tempo eu aproveito pra ouvir rádio”. (L. Horta, comunicação pessoal, Junho 16, 2015). Ele revela também que durante sua jornada de trabalho tem o costume usar fone de ouvidos conectados em seu celular que, por sua vez, transmite o som de uma emissora de rádio. 
O analista de sistemas Luiz Felipe Horta é ouvinte da emissora em função da interação que ela possui com o público. Eu mando twitte pra lá todos os dias e sempre me respondem. Eu me divirto bastante, além de me informar". (L. Horta, comunicação pessoal, Junho 16, 2015).

No quesito interatividade, a participação do internauta/ouvinte por e-mail está em declínio, pois as redes sociais roubam a cena dos ambientes virtuais. Portanto, a emissora divulga várias vezes ao dia o seu número do Whatsapp e os endereços do seu perfil no Instagran, Facebook e Twitter.

Vasconcellos conta que o Facebook e o e-mail são mais usados por ouvintes mais distantes que acessam a BandNews FM pela internet. Muitas vezes, este contato do ouvinte objetiva informar sobre a situação do trânsito em pontos específicos da região metropolitana de Belo Horizonte. Porém, isto requer cuidados da redação, pois há possibilidade de a informação não ser verdadeira: "A gente é claro tem que ter mais cuidado para apurar também, porque o ouvinte pode dizer uma coisa e essa coisa pode não ser tão assim da maneira que ele disse, mas fica muito mais gostosa a troca de informação". (B. Vasconcellos, comunicação pessoal, Junho, 2, 2015).

Agilidade é o ponto alto da emissora em estudo para a ouvinte jornalista Priscila Mendes. Ela destaca a possibilidade de o público participar ativamente da construção da notícia: "O rádio é tudo muito rápido, muito gostoso de se ouvir. Então se acontecer um acidente ali, é só ligar através do celular e você consegue passar a notícia. Então o que me encanta mesmo é a agilidade do rádio. (P. Mendes, comunicação pessoal, Junho, 15, 2015)

Ainda sobre a participação do público, Mendes avalia que esta seja o diferencial da BandNews, pois esta incentiva os ouvintes a participarem. Portanto, este papel ativo do ouvinte torna o ouvir rádio mais agradável: "Fica mais bacana, o ouvinte também se sente um pouquinho parte da rádio, ele se sente importante". (P. Mendes, comunicação pessoal, Junho, $15,2015)$

Horta reconhece que a BandNews é sua principal fonte de informação:" Eu tenho todas as notícias durante o dia inteiro". (L. Horta, comunicação pessoal, Junho 16, 2015). Porém, a 
petição das mesmas notícias ao longo da programação do dia é um limitador da all-news, na opinião do ouvinte Lyon Antunes: "Tem notícia que é muito repetida, eles nem trocam a pessoa que falou da última vez. É como se desse play numa notícia da semana passada, e isso as vezes é muito cansativo”. (L. Antunes, comunicação pessoal, Junho, 5, 2015)

Oliveira, porém, afirma que não há esta repetição apontada pelo ouvinte: “os assuntos voltam sempre à tona. Mas ai a gente altera o texto, o âncora tenta mudar o texto, acrescenta uma outra informação, outros tópicos importantes pra gente trazer pro nosso ouvinte. Então a gente vai reciclando o texto com novidades". (L. Oliveira, comunicação pessoal, Maio, 6, 2015). Na prática, é possível observar que nem sempre há esta modificação e reciclagem na informação, portanto, muitas vezes a notícia se repete na íntegra no decorrer do dia.

Sobre a repetição, Bufarah pondera que esta pode levar à sua situação de estresse na qual "a cada 15 minutos eu tenho alguém enlouquecido cavoucando informações por ai, pra dar essas informações de forma desordenada, de forma descompassada e acaba fazendo uma enxurrada, uma avalanche de conteúdo que enterra o ouvinte do outro lado" (A. Bufarah, comunicação pessoal, Junho, 20, 2015).

Neste contexto, os ambientes virtuais devem ser aliados para a boa informação, não sinônimo de informação sem embasamentos e credibilidade. "O rádio pode ganhar muito com a internet. (A. Bufarah, comunicação pessoal, Junho, 20, 2015). Portanto, as ferramentas para este bom trabalho existem, porém, para ele, faltam "criatividade e bom senso mínimo pra intercalar esses conteúdos de forma jornalística a dar um conteúdo diferenciado a esse ouvinte, dentro desse grande guarda-chuva que é o all-news”. (A. Bufarah, comunicação pessoal, Junho, 20, 2015).

O cidadão pode receber informação no celular, no tablet, no relógio, na TV, no rádio, na internet. São vários canais por onde se acessa informações. "O diferencial é dar a informação e contextualizar essa informação, para que esse cidadão possa ter noção do que está acontecendo e como isso se junta nesse grande emaranhado de dados e informações que ocorrem sobre nós todos os dias" (A. Bufarah, comunicação pessoal, Junho, 20, 2015). 


\section{Conclusões}

O formato de rádio all-news é de suma importância para o jornalismo dos tempos atuais. Isso porque ele mescla informação, análise e conversa, de uma maneira mais despojada, que ainda assim mantém credibilidade. Ele usa a força do rádio AM, com a informalidade do FM.

Ter apenas notícias na programação, sem veicular músicas, torna esse formato arriscado, já que o público também está interessado em entretenimento. Porém, quando a equipe de produção tem qualificação técnica e profissional e a emissora faz investimentos significativos, o all-news tem muito a ganhar e a proporcionar à população. Com bons profissionais, que sabem levar um tom de informalidade, mesmo na produção jornalística, o ouvinte pode ficar ainda mais fidelizado à emissora e ter confiança naquele "companheiro", que atualiza a todo momento os factos. Entretanto, é imprescindível que essa informalidade não afete a veracidade das notícias veiculadas ao público.

Nos tempos atuais, é muito fácil ter acesso às notícias, porque a internet revolucionou a forma de se fazer jornalismo. Talvez o rádio seja o veículo que mais se adequou a essa nova era, pois cativa o ouvinte e o permite a participar constantemente por meio das redes sociais. Com isso, o ouvinte também torna-se prioridade.

Aquelas emissoras que veiculam apenas notícias têm um público rotativo, já que poucos ouvem a mesma emissora durante todo o dia. As empresas estão conscientes disso e, então, buscam informar o máximo possível em intervalos curtos. Por isso, as rádios all-news utilizam os boletins em intervalos de quinze, vinte ou trinta minutos.

Uma questão a ser discutida é a forma como essas notícias são repassadas. O imediatismo não pode atropelar todas as etapas de produção de uma notícia, como apuração e checagem. Além disso, deve ser banida aquela situação de ler as páginas de jornais impressos no ar, que ocorria no início do formato aqui no Brasil. Isso também se aplica à internet.

\section{Referências}

Balsebre, A.(2013). O rádio está morto...Viva o som!" ou como o rádio pode se transformar em uma nova mídia. Significação. Revista de Cultura Audiovisual.2013.39,14-23. Retirado de: http://www.revistas.usp.br/significacao

Barbeiro, H.; Lima, P. R. (2003). Manual do Radiojornalismo: produção, ética e internet. Rio de Janeiro: Elsevier. 
Barbosa Filho, A. (2003). Gêneros Radiofônicos: os formatos e os programas em áudio. São Paulo: Paulinas.

Betti, J. G.; Meditsch, E. (2008). O formato all News no rádio brasileiro: importação, estranhamento e adaptação. Encontro Nacional de Pesquisadores em Jornalismo, 6, São Paulo, Brasil. Temático. São Paulo: UMESP, 2-12. Retirado de < http://sbpjor.kamotini.kinghost.net/sbpjor/admjor/arquivos/coordenada3eduardomeditsch.pdf>

Bufarah Junior, A.(2010). O radiojornalismo brasileiro diante das ferramentas de interação da web 2.0. In Schwingel, C.; Zanotti, C. (org.). Produção e Colaboração Digital. Florianópolis: Editora Insular.

Carneiro, L. (2002). Uma paixão chamada Itatiaia. Belo Horizonte: Tamoios Editora Gráfica. Ferratetto, L. A. (2013). O de lá e o de cá: apontamentos para uma categorização do conteúdo das emissoras comerciais brasileiras com base na influência do rádio dos Estados Unidos. Significação. Revista de Cultura Audiovisual. 39. 41-70.

Ferraretto, L. A. (2015). Rádio: Teoria e prática. São Paulo: Summus Editorial.

Grupo Bandeirantes de Comunicação [Band] 2005? Manual rápido dos padrões da BandNews FM, Belo Horizonte, Minas Gerais, Brasil. 12p.

Grupo Bandeirantes de Comunicação [Band] 2015]. Pioneirismo uma das marcas do Grupo.Retirado de Ghttp://www.band.uol.com.br/grupo/historia.asp.

Jung, M. (2011). Jornalismo de Rádio. 4 ed. São Paulo: Contexto.

Moreira, S. V. Jornalismo na rádio Jornal do Brasil. In Ortriwano, S. (Org.). Radiojornalismo no Brasil: dez estudos regionais. São Paulo: Com-arte, 1987.

Paula, P. A. (2006). Formato All News e a Fidelização do Ouvinte: A experiência das emissoras CBN Belo Horizonte e Band News FM. Monografia de Bacharelado em Comunicação Social, Centro Universitário de Belo Horizonte, Belo Horizonte, Minas Gerais, Brasil. Retirado de< http://www.convergencia.jor.br/bancomonos/2006/armani.pdf $>$.

Prado, M. (2012). História do Rádio no Brasil. São Paulo: Editora da Boa Prosa.

Tavares, M. (2011). Manual de Redação CBN. São Paulo: Globo. 